\title{
Geonics (Geomimetics) as a Theoretical Basis for New Generation Compositing
}

\author{
V. Lesovik ${ }^{1(\bowtie)}$, A. Volodchenko ${ }^{1}$, E. Glagolev ${ }^{1}$, I. Lashina ${ }^{1}$, \\ and H.-B. Fischer ${ }^{2}$ \\ ${ }^{1}$ Belgorod State Technological University Named After V.G. Shukhov, \\ Belgorod, Russia \\ naukavs@mail.ru \\ ${ }^{2}$ Bauhaus-Universität Weimar, Weimar, Germany
}

\begin{abstract}
The article introduces basic principles of a new transdisciplinary research area geonics (geomimetics) in the construction material science. This research area differs from bionics, which uses knowledge about nature to solve engineering problems. The purpose of geonics (geomimetics) is to solve engineering problems with the account of knowledge about geologic and cosmochemical processes.
\end{abstract}

Keywords: Geonics - Anthropogenic methasomatism in the construction material science $\cdot$ The law of consanguinity $\cdot$ Construction composites

\section{Introduction}

Nowadays many scientists are developing construction composites of new generations (Delgado et al. 2015; Ahadi 2011). Basing on the theoretical background of geonics (geomimetics) it is possible to reduce power consuming in construction materials production by application of energy of geological and cosmochemical processes, energy efficient raw material, specially treated with geological and cosmochemical processes.

So, production technologies for a wide range of composite binding materials (including water resistant and freeze proof gypsum binders) with the application of new raw material (Lesovik et al. 2014; Zagorodnyuk et al. 2018) with high free internal power have been suggested. Clay rocks with an incomplete stage of mineral formation and a sediment genesis zone, effusive rocks with an amorphous and cryptocrystalline structure, quartz rocks of greenschist coal ranging with crystalline defects and inclusions of mineral formation, gas and air inclusions, some kinds of anthropogenic materials and others refer to these materials (Elistratkin and Kozhukhova 2018).

\section{Methods and Approaches}

The law of consanguinity has been formulated within the theoretical backgrounds of geonics (geomimetics). It implies designing layered composites and maintenance systems at nano-, micro-, and macro- levels similar to basic matrix that enhances 
significantly material adhesion and durability. The implementation of this law allows creating a composite which components have close deformation and temperature characteristics.

The theory of anthropogenic methasomatosis in the construction material science has been suggested. This stage of composite materials evolution is characterized by composite ability to adjust to changing conditions during building and construction service. Designing construction composites with the account of anthropogenic methasomatosis theory in the construction material science provides possibility of selfhealing defects, which appear during construction and building service and design, they are so-called "smart" composites.

\section{Results and Discussion}

Principles for productivity enhancement of wall materials manufacturing using sandy and clay rocks with an incomplete stage of clay formation and industrial wastes in hydrothermal processing at atmospheric pressure have been suggested. It has been found that aeolian-sedentary-diluvia clay rocks of the Quaternary period are the products of the initial clay formation stage including metastable atelene minerals of nano-level and non-rounded finely dispersed quartz and are suitable as a raw material for autoclaved silicate materials production.

Application of sandy and clay rocks instead of traditional quartz sand in silicate materials production enhances raw mixture formation, hardens raw bricks by 4-11 times, that allows developing the production technique of highly-hollowed construction products.

Application of these rocks allows widening the range of autoclaved raw material base, decrease energy-output ratio of their production, improve the ecological state of the environment and create comfortable conditions for human life.

Within the law of consanguinity it has been found that rocks independent of their genesis (magmatic, methamorphic and aqueous) with banded texture, whose layers are introduced by minerals whose stress related characteristics and thermal-expansion coefficient differ significantly, are non-durable and have anisotropy coefficient 7-9 higher comparing with prototypes with anisotropy coefficient 2-3. Application of the suggested mixtures increases brickwork breaking limit by 3-5 times. It is explained by the contact zone microstructure, for example, ceramic brick and binding matrix. The designed binding matrix and wall material are nearly sole block sample and constructions with a traditional binding matrix have a distinct contact zone - the weakest place of the samples. This law allows creating restoration mixtures, plastering materials, brickwork and restoration compositions of new generations for every walling.

With the account of geonics theoretical background a wide range of acoustic, insulating, and construction insulating composites based on foam glass have been suggested.

Designing construction composites with the account of anthropogenic methasomatosis theory in the construction material science provides possibility of defects selfhealing which appear during construction and building service and design so-called "smart" composites. 
These materials are designed with the account of the system interacting with the environment. This system allows reacting to the external actions by defects "selfhealing" and having positive impact on the triad "a man-material-environment".

This approach has been tested on the composite bindings based on calc-sinter, which create favorable conditions for at the early stages of structure formation and system hardening. It decreases stress in the hardening composite and as a consequence decreases the amount and the size of micro-cracks that predetermines technical and economic efficiency of the composite binding based on tuff, especially in hot climate. Volcanic tuff is known to be a heteroporous rock. Pore space of this rock is rather complex in form and combines pores of different sizes.

Water in this rock is in complex interaction with its mineral grid, whose boundaries and ratio are relative and change constantly: vapour; chemically and physically bounded water; free or gravitational water.

In a hot climate, with a deficit of liquid phase in the concrete itself, tuff particles in the binding mixture composition, during the hardening process will release the capillary water, it will activate structure formation processes and synthesize more massive structure of the materials during concrete hardening and utilization.

The micro-cracks appearing during service at different conditions will self-heal by interaction of water in tuff particles with unreacted cement minerals. During service tuff particles release saved capillary water and that will result in structure formation activation and synthesizing more massive materials structure during concrete hardening and operation. These are so-called smart composites.

\section{Conclusions}

Hence, monodisciplinary and interdisciplinary approaches in the construction material science promoted developing a wide range of construction composites which main task is construction of solid and durable structures. Design and creation of materials for environment optimization "a man-material-environment" is a complex problem, which requires united work of scientists of different fields. A single way to solve this problem is transdisciplinary approach as a way of widening the scientific world view, which requires considering phenomena beyond a single science.

Acknowledgements. The study is carried out in the framework of the State Task of the RF Ministry of Education and Science No. 7.872.2017/4.6. Development of principles for the design of ecologically positive composite materials with prolonged bioresistance 2017-2019.

\section{References}

Ahadi P (2011) Applications of nanomaterials in construction with an approach to energy issue. Adv Mater Res 261-263:509-514

Delgado JMPQ, Cerný R, de Lima AGB, Guimarães AS (2015) Advances in building technologies and construction materials. Adv Mater Sci Eng 2015:1-3 no. 312613 
Elistratkin MY, Kozhukhova MI (2018) Analysis of the factors of increasing the strength of the non-autoclave aerated concrete. Constr Mater Prod 1(1):59-68

Lesovik VS, Chulkova IL, Zagorodnjuk LH, Volodchenko AA, Popov DY (2014) The role of the law of affinity structures in the construction material science by performance of the restoration works. Res J Appl Sci 9(12):1100-1105

Zagorodnyuk L, Lesovik VS, Sumskoy DA (2018) Thermal insulation solutions of the reduced density. Constr Mater Prod 1(1):40-50

Open Access This chapter is licensed under the terms of the Creative Commons Attribution 4.0 International License (http://creativecommons.org/licenses/by/4.0/), which permits use, sharing, adaptation, distribution and reproduction in any medium or format, as long as you give appropriate credit to the original author(s) and the source, provide a link to the Creative Commons license and indicate if changes were made.

The images or other third party material in this chapter are included in the chapter's Creative Commons license, unless indicated otherwise in a credit line to the material. If material is not included in the chapter's Creative Commons license and your intended use is not permitted by statutory regulation or exceeds the permitted use, you will need to obtain permission directly from the copyright holder. 